\title{
Neurofibromatosis type 1 with localized unilateral hyperhidrosis: A rare association
}

\section{Snehal Balvant Lunge, Anvitha Chidanand}

Department of Dermatology, Venereology and Leprosy, Jawaharlal Nehru Medical College, KLE University, Belagavi, India

Corresponding author: Dr. Snehal Balvant Lunge, E-mail: drsnehallunge@gmail.com

\begin{abstract}
Unilateral hyperhidrosis is a rare entity with primary and secondary causes. So far in literature, the associations documented with this entity rarely include neurofibromatosis. This association, however has been reported previously and perhaps is a more frequent incidence than is being recognized. Here we report a case to emphasize this association.
\end{abstract}

Key words: Localized unilateral hyperhidrosis; Neurofibromatosis type 1; Partial unilateral lentiginosis

\section{INTRODUCTION}

Localized unilateral hyperhidrosis (LUH) is a term coined to describe excessive sweating over a well circumscribed part of the body [1]. It is a rare entity and can be primary or secondary to other disorders (Table 1) [2]. We hereby report a case of an association between unilateral localized hyperhidrosis and Neurofibromatosis type 1 (NF 1), which seems to be a rare one as is evident from the lack of it's documentation in literature.

\section{CASE REPORT}

A 34-year-old female patient complained of profuse sweating over the fingers of her left hand, since childhood that had no obvious precipitating factors. The same area was affected always. There were no associated symptoms like by flushing, excessive salivation, lacrimation, orthostatic hypotension, causalgia or headache. The patient's past history was unremarkable with no history of trauma or any drug intake. Similar complaints were absent in the family.

On examination, the fingers of her left hand were moist. Starch-iodine test revealed localized areas of excessive sweating over the fingers of left hand (Fig. 1). On further examination, she had multiple brownish patches measuring more than $1 \mathrm{~cm}$, suggestive of cafe-au-lait macules scattered on both sides of the trunk and shoulders (Fig. 2). She had unilateral tiny hyperpigmented macules distributed over left side of face and neck including her left upper extremity, suggestive of Partial unilateral lentiginosis (PUL). Bilateral axillary freckling (Fig. 3) was observed. Ophthalmological examination revealed Lisch nodules on the iris of right eye (Fig. 4) and alterations in iris pigmentation. Magnetic Resonance Imaging of cervico thoracic region showed a plexiform neurofibroma (Fig. 5). The results of laboratory tests including endocrinological examination were normal. No abnormality was detected on magnetic resonance imaging of the brain and brainstem. The presence of cafe-au-lait macules $(>6,>1.5 \mathrm{~cm})$, axillary freckling, plexiform neurofibroma and lisch nodules confirmed the diagnosis of NFl according to the diagnostic criteria of NF 1 [3]. The patient had no cardiovascular or gastrointestinal complaints, and his chest X-ray was normal. The results of the complete blood count, hepatic and renal function tests were within the normal ranges. The histopathological examination of a skin biopsy of the hyperhidrotic area and symmetrically opposite side of normal skin showed no increase or abnormality of eccrine glands. The patient was diagnosed as having LUH and NF1.

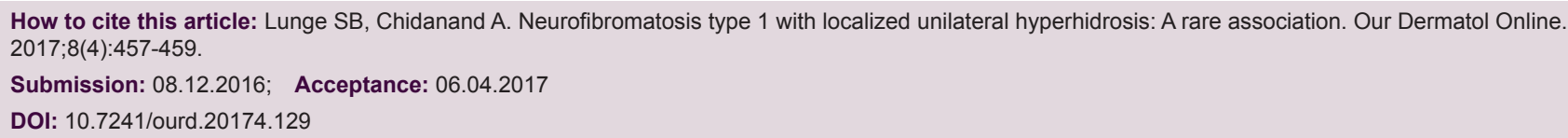


Table 1: Localized hyperhidrosis causes

Spinal cord injury
Hyperhidrosis associated with autonomic dysreflexia
Hyperhidrosis due to orthostatic hypotension
Gustatory hyperhidrosis
Frey's syndrome
Granulosis rubra nasi
Functional and true sweat gland naevi
Intrathoracic neoplasia
Sweating associated with local skin disorders
Glomangioma
Pachydermoperiostosis
Blue rubber bleb naevi
Pretibial myxoedema
Burning feet syndrome
POEMS syndrome
Idiopathic unilateral circumscribed hyperhidrosis
Compensatory
After sympathectomy, or with partial anhidrosis

POEMS, polyneuropathy, organomegaly, endocrinopathy, M protein, skin changes

\section{DISCUSSION}

Hyperhidrosis can be classified as emotional, generalized and localized [4]. Localized unilateral hyperhidrosis can be further categorized as gustatory, cutaneous-diseaseassociated and idiopathic variants [5]. The area of the body that demonstrates excessive sweating may give a clue to the cause; e.g. pathogenic gustatory sweating occurs mainly on the face, idiopathic hyperhidrosis is located mainly on the forearm and forehead of otherwise healthy people and is restricted to an area of less than $10 \times 10 \mathrm{~cm}$ [6]. Idiopathic LUH has none of the typical triggering factors found with essential hyperhidrosis. The attacks occur with no apparent cause even in sleep [7]. Cutaneous-disease-associated variant of LUH will have associated cutaneous features; e.g. palmoplantar keratodermas, glomus tumor, blue rubber bleb nevus, POEMS syndrome [8-11].

No discernible cause of hyperhidrosis could be found in our patient and the absence of triggering factors was compatible with idiopathic LUH. Skin biopsy of the hyperhidrotic site excluded associated cutaneous disorders. On physical examination, she had cafeau-lait macules $(>6,>1.5 \mathrm{~cm})$, axillary freckling and lisch nodules. She also had PUL over the left upper body. The lesions of partial unilateral lentiginosis can appear anywhere on the body but the upper extremities are more affected than the lower ones [12]. The coexistence of neurofibromatosis with partial unilateral lentigines raises the possibility that partial unilateral lentigines could be a variant or forme fruste of segmental neurofibromatosis [13]. Magnetic Resonance

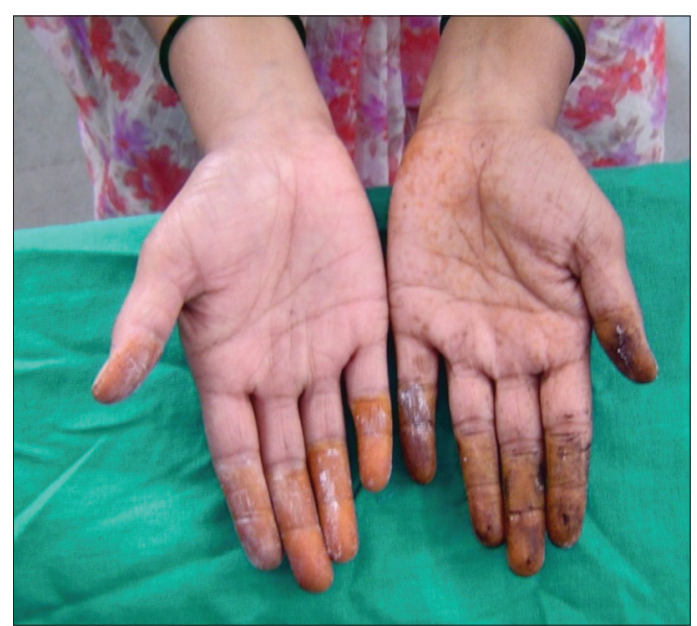

Figure 1: Starch iodine test demonstrating unilateral localized hyperhidrosis over fingers of the left hand.

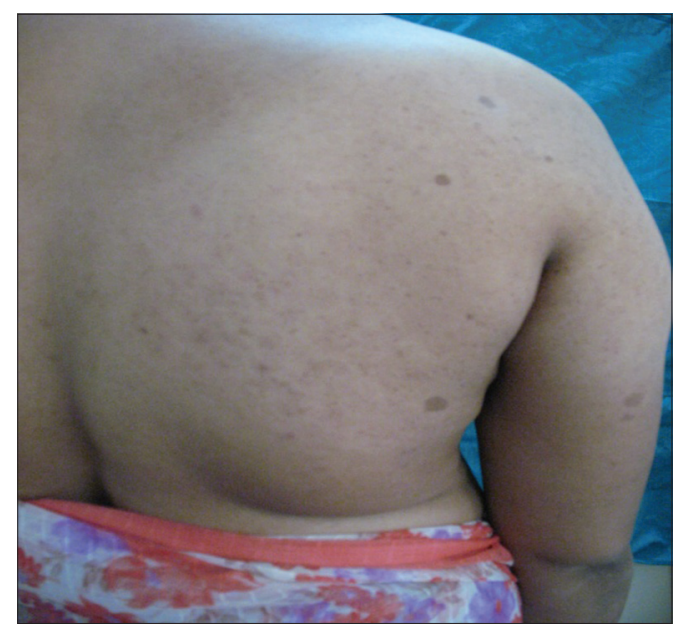

Figure 2: Cafe-au-lait macules, measuring $>1.5 \mathrm{~cm}$ scattered on the back.

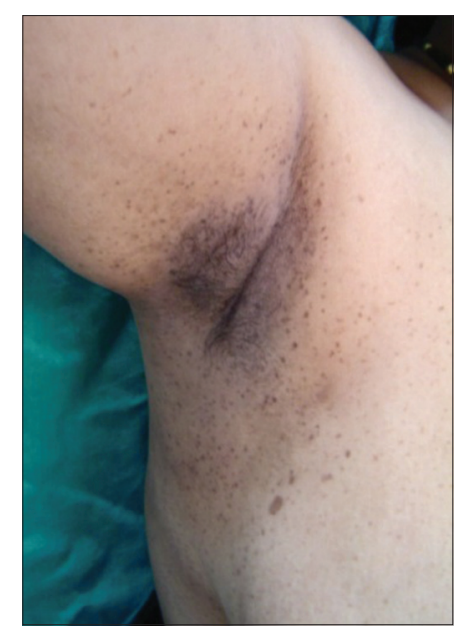

Figure 3: Axillary freckling (Crowe's sign).

Imaging of cervico thoracic region showed a plexiform neurofibroma. The case was categorized as NF1. NFl is 


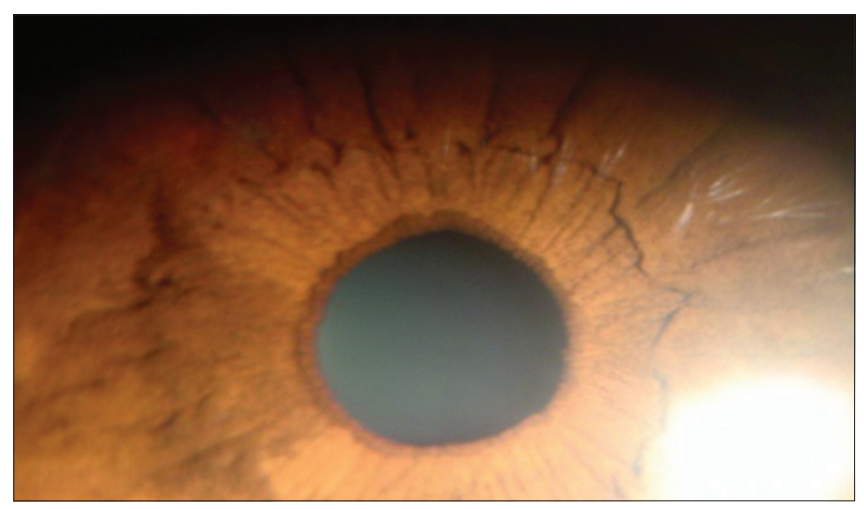

Figure 4: Lisch nodules with alterations in pigmentation.

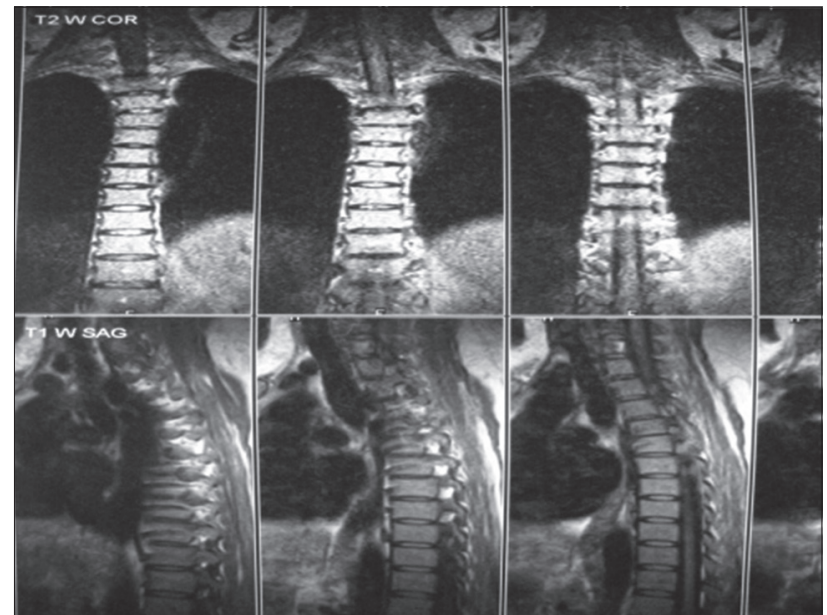

Figure 5: MRI of cervico thoracic region showing plexiform neurofibroma.

known to have many associations, but LUH has not been documented in the literature so far [6]. A case report of this association, however has been presented by Emel Bulbul Baskan et al in 2005 [14]. The pattern of LUH was different in that case and there was no conclusive evidence to support the association.

\section{CONCLUSION}

The lack of understanding of the etiopathogenesis of LUH is a major lacuna in detecting the underlying cause of this disorder, making the associated features difficult to elucidate. New associations will, perhaps be the gateway to better understanding of the underlying pathogenesis.

\section{REFERENCES}

1. Kreyden OP, Schmid-Grendelmeier P, Burg G. Idiopathic localized unilateral hyperhidrosis: case report of successful treatment with botulinum toxin type A and review of the literature. Arch Dermatol. 2001;137:1622-5.

2. Geattan CEH, Black AK. Disorders of sweat glands. In: Burns DA, Breathnach SM, Cox NH, Griffiths CEM. Rook's Textbook of Dermatology, 8th edition: Blackwell Publishing Ltd; 2008: 66. p. 66.16

3. Neurofibromatosis Conference statement.1988 National Institutes of Health consensus development conference. Arch Neurol. 1988;45:575-8.

4. Ghali FE, Fine JD. Idiopathic localized unilateral hyperhidrosis in a child. Pediatr Dermatol. 2000;1:25-8.

5. Sato K, Kang WH, Saga K, Sato KT. Biology of sweat glands and their disorders. II. Disorders of sweat gland function. J Am Acad Dermatol. 1989;20:713-726.

6. Ghali FE, Fine JD. Idiopathic localized unilateral hyperhidrosis in a child. Pediatr Dermatol. 2000;1:25-8.

7. Tsao H. Neurofi bromatosis and tuberous sclerosis; in Bolognia Jl, Jorizzo JL, Rapini RP (eds): Dermatology. Toronto, Mosby, 2003, pp 853-868.

8. van de Kerkhof PC, den Arend JA, Bousema MT, Stolz E. Localized unilateral hyperhidrosis. Br J Dermatol. 1987;117:779-82.

9. Aguilar P, Pique E, Gallego MA, Salvador C. Idiopathic localized unilateral hyperhidrosis. Actas Dermosifi liograf. 1998;89:422-4.

10. Cooke SAR. Misleading features in the clinical diagnosis of the peripheral glomus tumours. Br J Surg. 1971;58:602.

11. Fine RM, Derbes VJ, Clark WH. Blue rubber bleb nevus. Arch Dermatol. 1961;84:802-5.

12. Kanitakis J, Roger H, Soubrier M, Dubost JJ Chouvet B, Souteyrand P. Cutaneous angiomas in POEMS syndrome. Arch Dermatol. 1988;124:695-8.

13. Schaffer JV, Lazova R, Bolognia JL. Partial unilateral lentiginosis with ocular involvement. J Am Acad Dermatol. 2001;44:387-90.

14. Thompson GW, Diehl AK. Partial unilateral lentiginosis. Arch Dermatol. 1980;116:356.

Copyright by Snehal Balvant Lunge, et al. This is an open-access article distributed under the terms of the Creative Commons Attribution License, which permits unrestricted use, distribution, and reproduction in any medium, provided the original author and source are credited. Source of Support: Nil, Conflict of Interest: None declared. 